\title{
Antiepileptic Drugs, Polypharmacy, and Quality of Life in People Living with Epilepsy Managed in General Practice
}

\author{
Samuel Moran ${ }^{1,2} \quad$ Chris Peterson ${ }^{3,4} \quad$ Irene Blackberry \\ John Furler ${ }^{8}$ Graeme Shears ${ }^{4}$ Loretta Piccenna ${ }^{5,9}$ \\ 1John Richards Centre, La Trobe Rural Health School, \\ Wodonga, Victoria, Australia \\ ${ }^{2}$ Locum Medical Practitioner, Victoria, Australia \\ ${ }^{3}$ College of Arts, Social Sciences and Commerce, La Trobe \\ University, Bundoora, Victoria, Australia \\ ${ }^{4}$ Epilepsy Foundation, Surrey Hills, Victoria, Australia \\ ${ }^{5}$ Department of Medicine, Royal Melbourne Hospital, University of \\ Melbourne, Parkville, Victoria, Australia \\ ${ }^{6}$ Department of Neurology, St Vincent's Hospital, Fitzroy, Victoria, \\ Australia \\ ${ }^{7}$ Chronic Illness Alliance Moonee Ponds, Victoria, Australia \\ ${ }^{8}$ Department of General Practice and Primary Health Care, \\ University of Melbourne, Parkville, Victoria, Australia \\ ${ }^{9}$ Department of Neuroscience, Monash University, Prahran, \\ Victoria, Australia
}

Int J of Ep:2020;6:24-29
Mark Cook ${ }^{5,6}$ Christine Walker ${ }^{4,7}$

Address for correspondence Chris Peterson, BA, PhD, College of Arts, Social Sciences and Commerce, La Trobe University, Bundoora, Victoria 3086, Australia (e-mail: c.peterson@latrobe.edu.au).

\begin{abstract}
Keywords

- antiepileptic drugs

- epilepsy

- quality of life

Objective Recently, instances of general practitioners (GPs) prescribing antiepileptic drugs (AEDs) have increased. We aimed to investigate the use of AEDs in a community sample of people with epilepsy and the effect on quality of life (QoL).

Methods Responsesfrom the Australian Epilepsy LongitudinalStudy(AELS), Pharmaceutical Benefit Scheme (PBS), and Medicare Benefit Scheme (MBS) data were used. Linear regression was used to investigate the relationship between the numbers of AEDs and QoL.

Results Fifty people with epilepsy were prescribed an average of two AEDs. The most common were lamotrigine, sodium valproate, and levetiracetam. Eighty-two percent were prescribed medications from two or more categories of medications. A lower QoL at wave 2 of the AELS was significantly associated with a higher number of AEDs. Conclusion Given the high number of people with epilepsy being cared for in general practice, GPs must understand the risks and benefits of epilepsy monotherapy, polytherapy, and polypharmacy.
\end{abstract}

\section{Introduction}

In Australia more than $1 \%$ of people have epilepsy, a serious neurological condition. ${ }^{1}$ Epilepsy is characterized by the occurrence of either at least two unprovoked seizures, or one followed by at least two or more seizures over the following 10 years, and/or an epilepsy diagnosis. ${ }^{2}$ In new-onset epilepsy, seizures can often be successfully controlled with antiepileptic drugs (AEDs): 70 to $80 \%$ of people can achieve remission. ${ }^{3}$

The first AED in use was potassium bromide in 1857. This was followed by several other (first generation) AEDs, for 
example, phenobarbital, phenytoin, primidone, and ethosuximide. ${ }^{3}$ Some still remain in common use in Australia and generally have similar efficacy to newer agents, however, with a more significant side effect profile. ${ }^{4}$

In Australia, there was an increase in prescriptions of AEDs during the 5 years prior to $2007 .{ }^{5}$ Highest use was found in elderly people (age $\geq 80$ years). Sodium valproate was the most widely prescribed AED followed by carbamazepine and phenytoin. An increase in the prescribing of newer AEDs was observed in Australia, ${ }^{5}$ whereas in Canada there was a twofold increase in gabapentin use over 15 years (until 2013). ${ }^{6}$ Interestingly, between 2002 and 2007 in Australia the proportion of general practitioners (GPs) prescribing phenytoin was higher than their prescribing of any other AED. ${ }^{5}$ Furthermore, Hollingsworth and Eadie ${ }^{5}$ through an investigation of Medicare and drug utilization databases showed that an increase in prescribing newer AEDs in Australia had increased for GPs more than it had for nonpsychiatric specialists. Tan ${ }^{4}$ has reported that GPs will manage most adults with epilepsy.

\section{AEDs, Monotherapy, and Polypharmacy}

AEDs being developed recently are likely to have no greater efficacy than the ones currently in use due to their similar modes of action. ${ }^{7,8}$ Although a Cochrane systematic review found that withdrawals due to adverse events were reduced when patients had newer AEDs compared with the older-generation AED carbamazepine. ${ }^{9}$ In another study, seizure control was equivalent between the older generation AEDs-valproic acid and phenytoin-and newer AEDs, but more adverse events were reported by those individuals on older AEDs. ${ }^{3}$

Combining AEDs (polytherapy/polypharmacy) has been suggested in the management of epilepsy; however, it is not known whether this is more effective than monotherapy as there are several possible drug combinations and doses and no existing evidence from randomized clinical trials. Nonrandomized, controlled studies have suggested the combination or adjunctive use of the AEDs lamotrigine and sodium valproate in people with epilepsy not controlled by other medications. ${ }^{10}$

Additionally, antiepileptic polytherapy can have adverse side effects. ${ }^{11}$ Rational polypharmacy has involved looking at possible drug interactions with other drugs including AEDs to reduce side effects. ${ }^{12}$ However, no compelling evidence exists for differences in seizure outcome whether monotherapy or polytherapy was used. ${ }^{13}$

A recent study has shown that people with epilepsy who received AED monotherapy compared with polypharmacy experienced fewer ongoing seizures and reported a better quality of life (QoL) (when adjusting for seizure status). ${ }^{14}$ This was supported by a recent US study that showed AED polypharmacy was associated with a worse QoL, even when adjusting for severity of epilepsy..$^{15}$ One study found that AED polytherapy led to significantly less adverse reactions, ${ }^{16}$ although other studies found that QoL was better when changing to monotherapy, and it also reduced seizure frequency. ${ }^{17}$ An earlier study, however, found that side effects from AEDs did not significantly contribute to reduced QoL. ${ }^{18}$ However, a randomized controlled trial also found reduced numbers of AEDs were associated with significantly better QoL. ${ }^{19}$

Given that GPs are doing much of the prescribing of AEDs in Australia, ${ }^{4,5}$ clear evidence is required on the best AED regimens to prescribe to people with epilepsy and whether there is need to use multiple medications. The aim of this article is to document the prescription, and hence use, of AEDs in a community sample of people with epilepsy in an Australian setting. Further, it investigates the effect of AED use and polypharmacy on their QoL.

\section{Methods}

Data were collected from the Australian Epilepsy Longitudinal Study (AELS)-a survey using participants enrolled in the Australian Epilepsy Research Register (AERR). The AERR uses a self-selecting, community sample of people with epilepsy. It commenced in 2006 at the Epilepsy Foundation with a wave 1 survey (baseline data); wave 2 followed in 2010, wave 3 in 2013, and wave 4 in 2017. Having a diagnosis of epilepsy was the inclusion criteria.

Ethical approval was gained through Deakin University Human Research Ethics Committee (2013-011).

Participants in the wave 3 survey were asked for their consent to obtain and use their Medicare Benefit Scheme (MBS) and Pharmaceutical Benefit Scheme (PBS) data from the Department of Human Services. Data for those who consented were provided to the researchers on password-protected DVDs in Excel format. MBS and PBS data were collected in the period from early 2011 to late 2015 (an average of 4.5 years).

The QOLIE-31 test was used to measure QoL in participants. It is a 31-item scale developed by the Rand Corporation..$^{20}$ Cronbach's $\alpha$ was 0.93 . Test retest was 0.89 and internal consistency was 0.77 to $0.85{ }^{20}$

\section{Data Analysis}

Of the 324 participants enrolled in wave 3 of the AELS, MBS data were collected for 53 people and PBS data for 50 people. Survey responses from the AELS, and the PBS and MBS data obtained were analyzed using SPSS v24 (IBM SPSS Statistics for Windows, US). ${ }^{21}$ Counts and percentages, as well as means and standard deviations (SDs) were used for descriptive statistics. PBS data were used to determine which AEDs were prescribed and the total number of AEDs a participant was prescribed. The first level of the World Health Organization (WHO) anatomical therapeutical chemical (ATC) classification system was used to categorize the medications (other than AEDs) the participant had been prescribed.22 MBS data were used to determine the number of participants who were utilizing a GP chronic disease management plan. Linear regression was used to investigate the relationship between the number of AEDs and the number of different medication categories with the QOLIE-31score (i.e., quality of life). Scatterplots and $\mathrm{R}^{2}$ values were generated using SPSS v24. 


\section{Results}

\section{Participants}

Fifty participants had complete data and were included in this analysis. Of these $50,62 \%$ were female (-Table 1 ). The mean age of the participants was 49.4 years (SD 16.3 years; range 11-82 years). Thirty-eight percent of participants were in paid employment; $32 \%$ had attended high school to year 11 or below, $8 \%$ to year $12,20 \%$ had completed a trade or TAFE qualification, and $40 \%$ had completed tertiary studies; $46 \%$ were living with a partner and/or children; and $48.7 \%$ were living rurally.

Forty-eight percent of the participants had a chronic disease management plan developed by a GP (not specifically for epilepsy).

All participants had a diagnosis of epilepsy. The severity of epilepsy is shown in - Table $\mathbf{1}$.

- Table 2 shows the AEDs used by participants between 2011 and 2015. Most participants (94\%) had been prescribed at least one AED. On average participants were prescribed two different AEDs (mean 2.2; SD 1.2). The most common AEDs prescribed were lamotrigine ( $50 \%$ ), followed by sodium valproate (44\%) and levetiracetam (42\%). Three participants were not prescribed any AEDs during the study period. Participants that had reported having a seizure in the previous 12 months had a significantly higher mean number of AEDs prescribed $(p<0.001)$.

- Table 3 shows the categories of other medications that were prescribed. The WHO ATC classification system was used to group medications. ${ }^{22}$ All participants had been prescribed at least one medication during the study period. Eighty-two percent of participants had been prescribed medications from more than one ATC category. Most commonly, along with nervous system medications, these were anti-infective medications (78\% of participants), cardiovascular system medications ( $50 \%$ of participants), and alimentary tract and metabolism medications ( $48 \%$ of participants).

\section{Quality of Life}

A total of 24 participants had enough data to calculate their QOLIE-31 score at wave 2 and 32 participants had enough data to calculate their score at wave 4 , aged 18 years and older. The mean overall QOL for wave 2 was 57.21 (SD 23.06), while at wave 4 it was higher at 61.91 (SD 22.08).

A lower QoL at wave 2 was significantly associated with a higher number of AEDs a participant had been prescribed ( $\beta=-0.029 ; 95 \% \mathrm{CI}:-0.051,-0.007 ; p=0.011$ ). This relationship was still significant when adjusted for the participant's age, gender, highest level of education, employment status, and seizure activity ( $\beta=-0.026,95 \% \mathrm{CI}:-0.051,0.0001 ; p=0.048$ ).

No particular AED associated with QoL.

QoL was reinvestigated at wave 4 of the AELS. At wave 4 , QoL was no longer significantly related to the number of AEDs prescribed to a participant.

QoL was not significantly associated with the number of different ATC categories a participant had been prescribed medication from wave 2 or 4 .

Scatterplots with trend lines are shown in - Fig. 1 .
Table 1 Demographic information and severity of epilepsy for the sample of 50 from the Australian Epilepsy Longitudinal Study (AELS)

\begin{tabular}{|c|c|c|}
\hline \multicolumn{3}{|l|}{ Demographics } \\
\hline Gender & $n$ & $\%(N=50)$ \\
\hline Female & 31 & 62.0 \\
\hline Age & Mean & $\mathrm{SD}(N=50)$ \\
\hline Age & 49.4 & 16.3 \\
\hline Employment status & $N$ & $\%(N=50)$ \\
\hline Paid employment & 19 & 38.0 \\
\hline Highest level of education & $N$ & $\%(N=50)$ \\
\hline Year 11 or below & 16 & 32.0 \\
\hline Year 12 & 4 & 8.0 \\
\hline Trade or TAFE & 10 & 20.0 \\
\hline Tertiary & 20 & 40.0 \\
\hline Living in the city or country? & $n$ & $\%(N=39)^{\mathrm{a}}$ \\
\hline Country & 19 & 48.7 \\
\hline Partner status & $n$ & $\%(N=50)$ \\
\hline $\begin{array}{l}\text { Living with partner and/or } \\
\text { children }\end{array}$ & 23 & 46.0 \\
\hline GP care plan? & $n$ & $\%(N=50)$ \\
\hline Yes & 24 & 48.0 \\
\hline \multicolumn{3}{|l|}{ Epilepsy } \\
\hline $\begin{array}{l}\text { Number of seizures in past } \\
12 \text { months }\end{array}$ & $n$ & $\%(N=49)^{a}$ \\
\hline None & 23 & 46.9 \\
\hline Less than 1 per month & 13 & 26.5 \\
\hline 1 or more per month & 9 & 18.4 \\
\hline 1 or more per week & 4 & 8.2 \\
\hline Injuries resulting from epilepsy & $n$ & $\%(N=49)^{a}$ \\
\hline $\begin{array}{l}\text { Have you been injured as a result } \\
\text { of a seizure in the past } 3 \text { years? }\end{array}$ & 16 & 32.7 \\
\hline Surgery to treat epilepsy & $n$ & $\%(N=50)$ \\
\hline $\begin{array}{l}\text { Have you had surgery for } \\
\text { epilepsy? }\end{array}$ & 12 & 24.0 \\
\hline
\end{tabular}

aMissing responses.

\section{Discussion}

The medications prescribed to a community-based sample of 50 participants with epilepsy were investigated to determine the use of AEDs, levels of polypharmacy, and the relationship with QoL. The fact that just under half of the participants in this study were under a GP chronic disease management plan suggests that GPs are often involved directly in the health care of people with epilepsy.

This study shows people with epilepsy are often prescribed multiple AEDs (polytherapy/polypharmacy), as well as being prescribed medications from other medication classes (for other indications) alongside their AEDs.

On average, participants were prescribed two AEDs between 2011 and 2015. These most commonly were lamotrigine $(50 \%)$, sodium valproate $(44 \%)$, and levetiracetam 
Table 2 Antiepileptic drugs (AEDs) prescribed to the cohort

\begin{tabular}{|c|c|c|}
\hline & Mean/count & $\begin{array}{l}\text { Standard } \\
\text { deviation, \% }\end{array}$ \\
\hline $\begin{array}{l}\text { Total number of AEDs } \\
\text { prescribed per participant }\end{array}$ & 2.2 & 1.229 \\
\hline \multicolumn{3}{|l|}{ Number of AEDs } \\
\hline No AEDs & 3 & 6.0 \\
\hline $1 \mathrm{AED}$ & 12 & 24.0 \\
\hline 2 AEDs & 16 & 32.0 \\
\hline 3 AEDs & 13 & 26.0 \\
\hline 4 AEDs & 3 & 6.0 \\
\hline 5 AEDs & 3 & 6.0 \\
\hline $\begin{array}{l}\text { Percentage of cohort } \\
\text { prescribed each common } \\
\text { AED medication informed } \\
\text { by Tan (2014) }\end{array}$ & $n$ & $\%(N=50)$ \\
\hline Lamotrigine & 25 & 50.0 \\
\hline Valproate & 22 & 44.0 \\
\hline Levetiracetam & 21 & 42.0 \\
\hline Carbamazepine & 9 & 18.0 \\
\hline Clonazepam & 6 & 12.0 \\
\hline Gabapentin & 4 & 8.0 \\
\hline Topiramate & 4 & 8.0 \\
\hline Pregabalin & 3 & 6.0 \\
\hline Phenytoin & 1 & 2.0 \\
\hline Oxcarbazepine & 1 & 2.0 \\
\hline $\begin{array}{l}\text { Percentage of cohort } \\
\text { prescribed other AEDs } \\
\text { registered on the PBS for use } \\
\text { in epilepsy }\end{array}$ & $n$ & $\%(N=50)$ \\
\hline Zonisamide & 7 & 14.0 \\
\hline Lacosamide & 5 & 10.0 \\
\hline Ethosuximide & 1 & 2.0 \\
\hline Acetazolamide & 1 & 2.0 \\
\hline
\end{tabular}

${ }^{a}$ No participants were prescribed phenobarbitone, primidone, nitrazepam, vigabatrin, tiagabine, perampanel, or sulthiame.

(42\%). This differs from an earlier study that showed sodium valproate as the most widely prescribed AED. ${ }^{5} \operatorname{Tan}^{4}$ described the AEDs approved for use in Australia prior to 2010. The AEDs, zonisamide and lacosamide, had only been recently registered at the time Tan wrote for Australian Family Physician. Of note, these newer agents were prescribed to $14 \%$ and $11 \%$, respectively, of our participants.

Commonly, participants had been prescribed medications from more than one ATC category; 52\% having been prescribed medications from greater than five different ATC categories. The three most common ATC categories of medications prescribed to participants other than "nervous system" medications were "anti-infectives" (78\%), such as antibiotics; "cardiovascular system" medications (50\%), such as antihypertensives; and "alimentary tract and metabolism" medications (48\%), such as antiemetics. While there
Table 3 Other medications prescribed to the cohort (utilizing WHO ATC classification system) $)^{22}$

\begin{tabular}{|l|l|l|}
\hline $\begin{array}{l}\text { Number of different categories } \\
\text { of medication a participant had } \\
\text { been prescribed medications from }\end{array}$ & $\mathbf{n}$ & $\%(\boldsymbol{N}=\mathbf{5 0})$ \\
\hline 1 & 9 & 18.0 \\
\hline 2 & 2 & 4.0 \\
\hline 3 & 9 & 18.0 \\
\hline 4 & 4 & 8.0 \\
\hline 5 & 6 & 12.0 \\
\hline 6 & 8 & 16.0 \\
\hline 7 & 7 & 14.0 \\
\hline 8 & 3 & 6.0 \\
\hline 9 & 2 & 4.0 \\
\hline
\end{tabular}

Percentage of the cohort prescribed other medication(s) from each ATC category of medication

\begin{tabular}{|c|c|c|}
\hline Nervous system & 48 & 96.0 \\
\hline Anti-infectives for systemic use & 39 & 78.0 \\
\hline Cardiovascular system & 25 & 50.0 \\
\hline $\begin{array}{l}\text { Alimentary tract and } \\
\text { metabolism }\end{array}$ & 24 & 48.0 \\
\hline Musculoskeletal system & 20 & 40.0 \\
\hline Dermatologicals & 15 & 30.0 \\
\hline Sensory organs & 14 & 28.0 \\
\hline $\begin{array}{l}\text { Genitourinary system and sex } \\
\text { hormones }\end{array}$ & 13 & 26.0 \\
\hline Respiratory system & 10 & 20.0 \\
\hline $\begin{array}{l}\text { Blood and blood forming } \\
\text { organs }\end{array}$ & 8 & 16.0 \\
\hline $\begin{array}{l}\text { Systemic hormonal prepara- } \\
\text { tions, excluding sex hormones } \\
\text { and insulins }\end{array}$ & 6 & 12.0 \\
\hline $\begin{array}{l}\text { Antineoplastic and immuno- } \\
\text { modulating agents }\end{array}$ & 2 & 4.0 \\
\hline Various & 1 & 2.0 \\
\hline $\begin{array}{l}\text { Antiparasitic products, insecti- } \\
\text { cides, and repellents }\end{array}$ & 0 & 0.0 \\
\hline
\end{tabular}

are varying definitions of polypharmacy, there is widespread acceptance that as the number of different medications that are being taken increases, a person's risk of drug interactions increases, as well as their "pill burden." These results suggest that people with epilepsy are commonly prescribed other medications alongside their AEDs and are at an increased risk of the negative implications of polypharmacy.

QoL decreased significantly with the number of AEDs a participant was prescribed at wave 2 of the AELS but was not significant in wave 4 . One explanation is that total QoL increased substantially from wave 2 to wave 4 . This may have been reflected in overall more positive effects of variables such as increased number of AEDs on QoL in wave 4 . Although we were only able to show a modest relationship, our data elude to a higher number of AEDs being associated with a lower QoL among a community-based sample of 


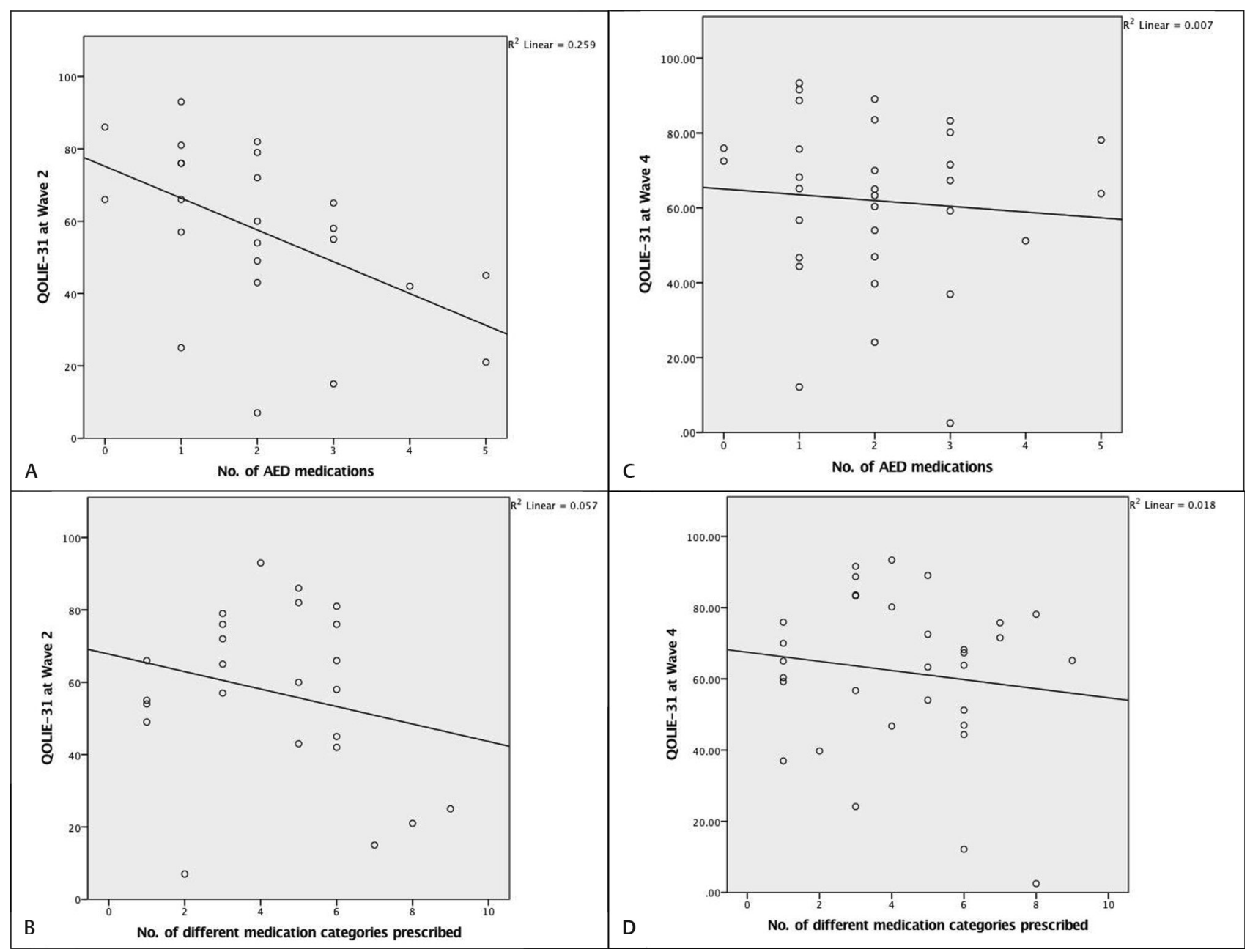

Fig. 1 Scatterplots with trend lines demonstrating the relationship between number of AEDs and number of different ATC categories and quality of life (QOLIE-31). The $\mathrm{R}^{2}$ value of the trend lines are displayed next to each plot. (A) Several AEDS by QoL in Wave 2; (B) number of medication categories by QoL in Wave 2; (C) number of AEDs by QoL in Wave 4; and (D) number of medication categories by QoL in Wave 4.

people with epilepsy in Australia, even when adjusting for severity of epilepsy. This is consistent with the findings of Alexander et $\mathrm{al}^{15}$ in a recent study from the United States that showed lower QoL was associated with AED polypharmacy, as well as the findings of several other studies. ${ }^{14,17,19} \mathrm{QoL}$ was not significantly related to the number of different ATC categories a participant had been prescribed medications from.

Given that there is limited evidence for the effectiveness in seizure control whether AED monotherapy or polytherapy is used ${ }^{13}$ and that AED polytherapy may be associated with a lower QoL, there seems little compelling need to use AED polytherapy in the management of epilepsy.

\section{Limitations and Strengths}

This was a small sample derived from the AELS, and hence the results may not be generalizable to the entire epilepsy population in general practice. However, this analysis was designed to display a snapshot of prescribing behavior for those with epilepsy and provide some insight into the levels of polypharmacy in this patient group. In general specialists are the first to determine and prescribe AEDs, while only some GPs initially prescribe. However, this study did not identify the initial prescriber.

Additionally, this study did not look at the duration that each participant was prescribed each AED. This study is based on prescription data rather than self-reported drug-taking behavior, potentially not reflecting the true drug usage of the participant.

\section{Conclusion}

People with epilepsy in this community-based sample were often prescribed more than one anti-epileptic medication (AED). Lamotrigine, sodium valproate, and levetiracetam were the most commonly prescribed AEDs. People with epilepsy are often cared for by GPs. GPs should be aware of the morbidity associated with AEDs and polypharmacy, and attempt to rationalize patients' medications where appropriate.

\section{Funding}

This work was funded by UCB Pharma. 


\section{Conflict of Interest}

None declared.

\section{Acknowledgments}

The authors thank UCB Pharma for providing funding for the longitudinal research on which this article is based. They also wish to thank the people from the AELS who consented to having their PBS details used in this study.

\section{References}

1 Brown K, Indicators of the social consequences of epilepsy. In: Pinicinhara J, Walker C, eds. Society Behaviour and Epilepsy. New York: Nova Biomedical; 2011 17- 28

2 Fisher RS, Acevedo C, Arzimanoglou A, et al. ILAE official report: a practical clinical definition of epilepsy. Epilepsia 2014;55(4):475-482

3 Schmidt D, Schachter SC. Drug treatment of epilepsy in adults. BMJ 2014;348:g254

4 Tan M. Epilepsy in adults. Aust Fam Physician 2014;43(3): 100-104

5 Hollingworth SA, Eadie MJ. Antiepileptic drugs in Australia: 2002-2007. Pharmacoepidemiol Drug Saf 2010;19(1):82-89

6 Leong C, Mamdani MM, Gomes T, et al. Antiepileptic use for epilepsy and non-epilepsy disorders: a population-based study (1998-2013) Neurology 2016;86:939-946

7 Zaccara G, Schmidt D. Do traditional anti-seizure drugs have a future? A review of potential anti-seizure drugs in clinical development. Pharmacol Res 2016;104:38-48

8 Wilby J, Kainth A, Hawkins N, et al. Clinical effectiveness, tolerability and cost-effectiveness of newer drugs for epilepsy in adults: a systematic review and economic evaluation. Health Technol Assess 2005;9(15):1-157, iii-iv

9 Talati R, Scholle JM, Phung OJ, et al. Effectiveness and safety of antiepileptic medications in patients with epilepsy. Comparative Effectiveness Review No 40. Agency for Healthcare Quality and Research. Rockville: AHRQ Publications; 2011

10 Kwan P, Schachter SC, Brodie MJ. Drug-resistant epilepsy. N Engl J Med 2011;365(10):919-926
11 St Louis EK. Minimizing AED adverse effects: improving quality of life in the interictal state in epilepsy care. Curr Neuropharmacol 2009;7(2):106-114

12 Rational AED. Polypharmacy-what are the criteria for providing optimal care? Neurol Rev 2009;17:3-12

13 Schmidt D. Drug treatment strategies for epilepsy revisited: starting early or late? One drug or several drugs? Epileptic Disord 2016;18(4):356-366

14 Polypharmacy alone worsens quality of life in epilepsy. Editorial Neurology Advisor Dec 2016 Reporting on Briglia H, Quigg M, Broshek D. Polypharmacy is associated with worse quality of life in epilepsy. Presented at: 2016 American Epilepsy Society Annual Meeting. December 2-6, 2016; Houston, TX. Available at: http://www.neurologyadvisor.com/ aes-2016-coverage/polypharmacy-alone-worsens-qualityof-life-in-epilepsy/article/576857. Accessed March 3, 2017

15 Alexander HB, Broshek DK, Quigg M. Quality of life in adults with epilepsy is associated with anticonvulsant polypharmacy independent of seizure status. Epilepsy Behav 2018;78:96-99

16 George J, Kulkarni C, Sarma GRK. Antiepileptic drugs and quality of life in patients with epilepsy: a tertiary care hospital-based study. Value Health Reg Issues 2015;6:1-6

17 Pirio Richardson S, Farias ST, Lima AR III, Alsaadi TM. Improvement in seizure control and quality of life in medically refractory epilepsy patients converted from polypharmacy to monotherapy. Epilepsy Behav 2004;5(3):343-347

18 Suurmeijer TPBM, Reuvekamp MF, Aldenkamp BP. Social functioning, psychological functioning, and quality of life in epilepsy. Epilepsia 2001;42(9):1160-1168

19 Uijl SG, Uiterwaal CS, Aldenkamp AP, et al. Adjustment of treatment increases quality of life in patients with epilepsy: a randomized controlled pragmatic trial. Eur J Neurol 2009;16(11): $1173-1177$

20 Vickery BG, Perrine KR, Hays RO, et al. Quality of life in epilepsy QOLIE-31(Version 1.0) Scoring Manual, US: Rand; 1993

21 IBM Corp IBM SPSS Statistics for Windows, Version 24.0. 2016; Armonk, NY: IBM Corp

22 World Health Organization (WHO), Anatomical Therapeutical Chemical Classification. Uppsala, Sweden: Nordic Council on Medicines; 1997 